\title{
Prognostic Value of the Ocular Trauma Score (OTS) In Open Globe Injuries at North Bengal Medical College, Darjeeling, West Bengal
}

\author{
Dr Pinaki Sengupta ${ }^{1}$, Dr Mahua Mazumdar ${ }^{2}$, Dr Amalesh Panda ${ }^{3}$ \\ ${ }^{1}$ Assistant Professor, Ophthalmology, North Bengal Medical College, Darjeeling. \\ ${ }^{2}$ Assistant Professor, Ophthalmology, College of Medicine and Sagore Dutta Hospital, Kolkata \\ ${ }^{3}$ Post Graduate Trainee, Ophthalmology, North Bengal Medical College, Darjeeling. \\ Jawpur Road, Behind Kalindi Housing, Kolkata
}

\begin{abstract}
Introduction: Worldwide, the Ocular Trauma Score (OTS) standardizes the prognosis of ocular injuries based on clinical criteria and provides the best achievable results in the treatment of such cases. Open Globe Injuries are a major but preventable cause of permanent visual impairment and blindness in the world. The Ophthalmology department of the North Bengal Medical College and Hospital treats a large number of OGI cases.

Objectives: The present study attempts to determine the visual outcomes in patients with OGIs and to determine visual prognosis following an eye injury as compared to the OTS study.

Materials and methods: A descriptive cross sectional study was conducted among all patients admitted in the Ophthalmology department of the North Bengal Medical College and Hospital between January 2013 and December 2014. Patients were classified based on the OTS scores and reassessed at 6 months post treatment using predesigned and pretested schedule.

Results: Final analysis was conducted in the 115 with a mean follow up of 7.2 months. The mean age was 29.4 \pm 15.6 years. Most (80\%) of the patients were adults and approximately two-thirds $(78.3 \%)$ of the patients were males. The most common place of being injured was at work (55.7\%). Globe ruptures (53\%) were the most common while lacerations constitute $47 \%$ of OGI injuries. The difference in the outcomes of the present study with the OTS is depicted graphically in the figures. .

Discussion and conclusions: The visual outcome of patients with OTS category I, II and III, six months after an injury can be reasonably ascertained by the Ocular Trauma Scoring (OTS) system.
\end{abstract}

\section{Introduction}

Worldwide, the Ocular Trauma Score (OTS), suggested by Kuhn et al. standardizes the prognosis of ocular injuries based on clinical criteria and provides the best achievable results in the treatment of such cases. Open globe injury, defined as a full thickness wound of the eye wall, is a major but preventable cause of permanent visual impairment and blindness in the world.

North Bengal Medical College is a Medical College and Hospital located in the Darjeeling district of West Bengal. The Ophthalmology department of the hospital caters to populations in the vicinity of the hospital and also acts as a referral centre for cases from the nearby districts as well as Nepal and Bhutan. It treats a large number of OGI cases everyday by virtue of being the only tertiary care eye treatment facility in the area. However, prognosis of such treated patients as compared to the OTS study has not been assessed till date.

\section{Objectives}

The present study attempts to determine the visual outcomes in patients who sustained OGIs (and were admitted to the Ophthalmology department of NBMC) and to determine whether the visual prognosis following an eye injury differs from the predicted outcomes according to the OTS study.

\section{Materials And Methods}

Study type \& design: Descriptive study with cross sectional design.

Study period: The study was conducted between January 2013 and December 2014

Study setting: The present study was conducted at the North Bengal Medical College and Hospital, a tertiary care hospital of eastern India. The hospital is the largest government healthcare facility in the eastern part of India serving as a tertiary referral institute and has teaching programs for graduation and post-graduation.

Study Population: Patients attending the Ophthalmology department of NBMC with Open Globe Injuries (OGI) 
Sample size: Complete enumerations of all patients that attended the hospital during the study period and were available at follow up at 6 months were included in the study.

Sampling techniques: All consecutive patients with Open Globe were included in the present study.

Data collection tools: Data was collected using a predesigned and pretested schedule containing sections on demographic data, disease characteristics, ophthalmological findings at presentation and Ophthalmological findings at 6 months.

Data collection technique: Data were collected from consecutive patients with Open Globe Injuries (OGI) that were admitted at the ophthalmology inpatient at the North Bengal Medical College. All patients were advised follow up at the Ophthalmology outpatient department every month for a period of 6 months following discharge.

Data analysis: Data was analysed using principles of descriptive statistics.

Ethical committee approval: Prior to conduction of the study, permission was obtained from the college authorities and ethical clearance from the Institution Ethics Committee. Informed consent was taken from each patient before collecting data, after assuring confidentiality and anonymity of the information.

\section{Results}

A total of 131 patients were admitted in the department during the study period. 21 patients were lost to follow up. Analysis was conducted in the 115 patients that came for follow up at 6 months. The mean duration of follow up was 7.2 months (6.1 to 8 months). Table 1 shows that the mean age of patients admitted at the Ophthalmolgy department of North Bengal Medical College was $29.4 \pm 15.6$ years. Most (80\%) of the patients were adults while children and elderly were 15.7 and $4.3 \%$ respectively. Approximately two-thirds (78.3\%) of the patients were males. The most common place of being injured was at work $(55.7 \%)$, while the least number of patients received OGI due to violence $(0.9 \%)$. Figure 1 shows the classification of the study population according to the BETTS classification, Globe ruptures (53\%) are the most common of the OGIs admitted to the Ophthalmology department of the NBMC. Lacerations constitute $47 \%$ of OGI injuries in the present sample. Among all OGIs penetrating injuries without retinal detachment or Vitreous hemorrhage are the most common (32.2\%). Corneal rupture without involvement of the Retina and Vitreous (20\%) are the second most common cause of OGI in the present study. Figure 2 shows the expected (Ocular Trauma Score study) prognosis and the prognosis seen in the present study. The first bar diagram shows the prognosis of the study population as compared to the OTS study among patients with OTS 1 . The second bar diagram compares the prognosis of OTS 2 patients in the present and the OTS study while the third bar diagram compares the two in OTS 3 patients.

\section{Discussion}

Ocular injuries presenting to the ophthalmology department in the North Bengal Medical College are more common in adults. Even among admitted patients with OGI, adult males were more commonly affected. Although a male predominance in the present study was similar to those noted among patients with OGI in other studies, the mean age in the present study was much lower than that in these studies.' An earlier study from the same institution has reported around $17 \%$ of ocular injuries in children less than 14 years of age at the outpatient ophthalmology department. The lower mean age of the present cohort could be due to the large number of patients in this age group $(15.7 \%)$.

Almost half of all types of ocular injuries in the region have been seen to be linked to the workplace including agricultural works. This high annual incidence of eye injuries in agriculture, even higher than the rates in industries in India, is probably related to the lower use of personal protective equipments at work. A study by Saari and Aine in Finland, which analysed various injuries in agricultural workers (superficial, blunt and penetrating), found that the blindness rate was as high as $21.9 \%$. Among OGIs, the workplace was the commonest site of sustaining injuries thereby reiterating the need to institute training regarding workplace safety and the use of protective measures at the workplace. Even when protective eyewear was available for $48.6 \%$ of these patients, only a fifth $(19.4 \%)$ wore it.

OTS provides an objective assessment of eye injuries and helps in the prognosticating of vision upto $77 \%$ (plus or minus) within one visual category. An accurate prediction of prognosis helps in management decisions as well as forecasting patient expectations, "the OTS is easy to calculate and has major significance for the injured patient, for the treating ophthalmologist, and for all other public health professionals who are interested in the eye injury scene in general". The usefulness of the OTS in serious eye injuries, in different settings and age groups, has been shown in studies from several parts of the world including India.

The visual outcome of OTS category I, II and III, six months after an injury in the present study was almost similar to that reported in the OTS study probably due to the presence of a state of the art ophthalmological treatment facility at the hospital. Results, statistically similar to the OTS study were seen in patients with OGI in South Africa, Pakistan and India. Although, many of the patients that attended the study 
centre are brought in late with an increased risk of developing endopthalmitis post-operatively, the final outcome is not significantly lower. Patients with raw scores between 81 and 100 (category IV and V patients), carry a better prognosis, and are not referred to the tertiary care hospital for treatment. The absence of OTS category 4 and 5 patients in the present cohort could be the result of this selective referral as injuries with higher raw scores can be managed in the government primary and secondary care set ups in West Bengal.

\section{Conclusion}

The visual outcome of patients with OTS category I, II and III, six months after an injury can be reasonably ascertained by the Ocular Trauma Scoring (OTS) system.

\section{Limitations}

Patients included in the study do not represent the profile of all eye injuries in the region as a large section of the patients attend alternative care delivery centres both at the government and private sectors. Again, the study being a retrospective record based one, researchers could use only the data recorded in the registers. Detailed socio-demographic records were not kept at the institute records and hence not included in the study. Delayed presentation and the presence of endopthalmitis in the patients were not included as study variables and could have impacted the outcome in these patients. No active follow-up of the patients were undertaken and hence the long term outcome of the patients were not available.

\section{Acknowledgement}

The authors would like to thank Dr Abhijit Mukherjee, Assistant Professor, Department of Community Medicine for his help in the preparation of the manuscript and statistical calculations.

Table 1: Demographic and injury related characteristics of patients admitted with Open Globe Injuries

\begin{tabular}{|l|l|c|c|}
\hline \multicolumn{2}{|l|}{ Variable } & Statistics & Percentage \\
\hline \multirow{3}{*}{ Mean age } & \multicolumn{2}{|c|}{$29.4 \pm 15.6$ years } \\
\hline \multirow{4}{*}{ Age groups } & Children (<14 years) & 18 & 15.7 \\
\cline { 2 - 4 } & Adults & 92 & 80.0 \\
\cline { 2 - 4 } & Elderly (age > 60 years) & 5 & 4.3 \\
\hline \multirow{3}{*}{$\begin{array}{l}\text { Place of } \\
\text { occurrence }\end{array}$} & Female & 25 & 21.7 \\
\cline { 2 - 4 } & Male & 90 & 78.3 \\
\cline { 2 - 4 } & Home & 20 & 17.4 \\
\cline { 2 - 4 } & Others & 6 & 5.2 \\
\cline { 2 - 4 } & RTA & 9 & 7.8 \\
\cline { 2 - 4 } & School/ sports & 15 & 13.0 \\
\cline { 2 - 4 } & Violence & 64 & 0.9 \\
\cline { 2 - 4 } & Work & & 55.7 \\
\hline
\end{tabular}

Figure 1: Patterns of OGI according to the BETTS calssification

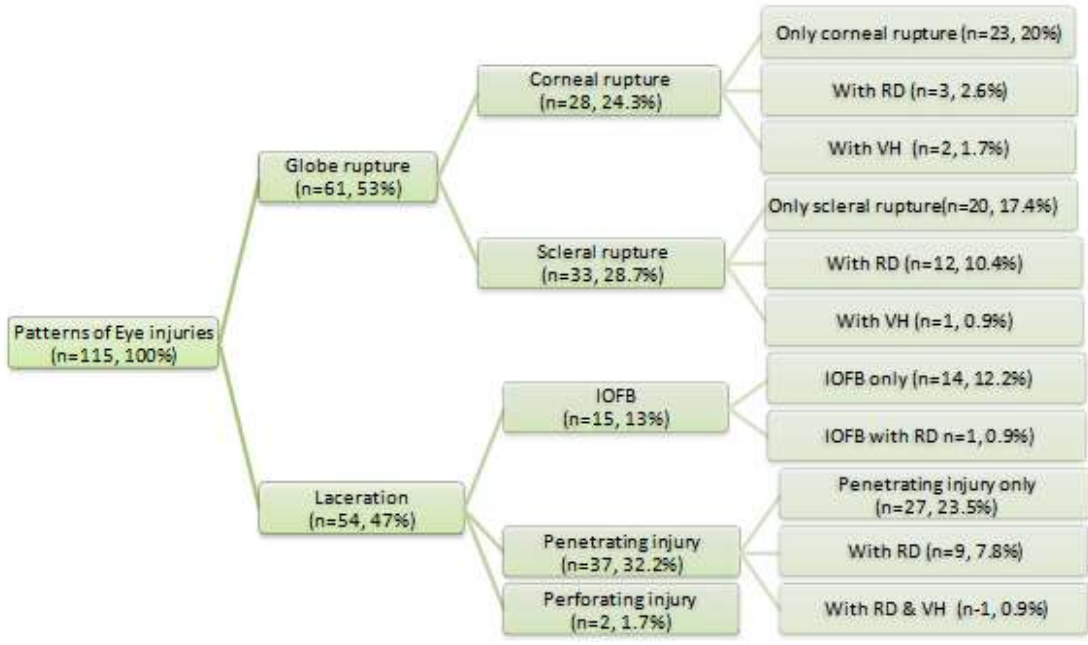

Figure 2: Figure showing the expected (Ocular Trauma Score study) prognosis and the prognosis seen in the present study. 


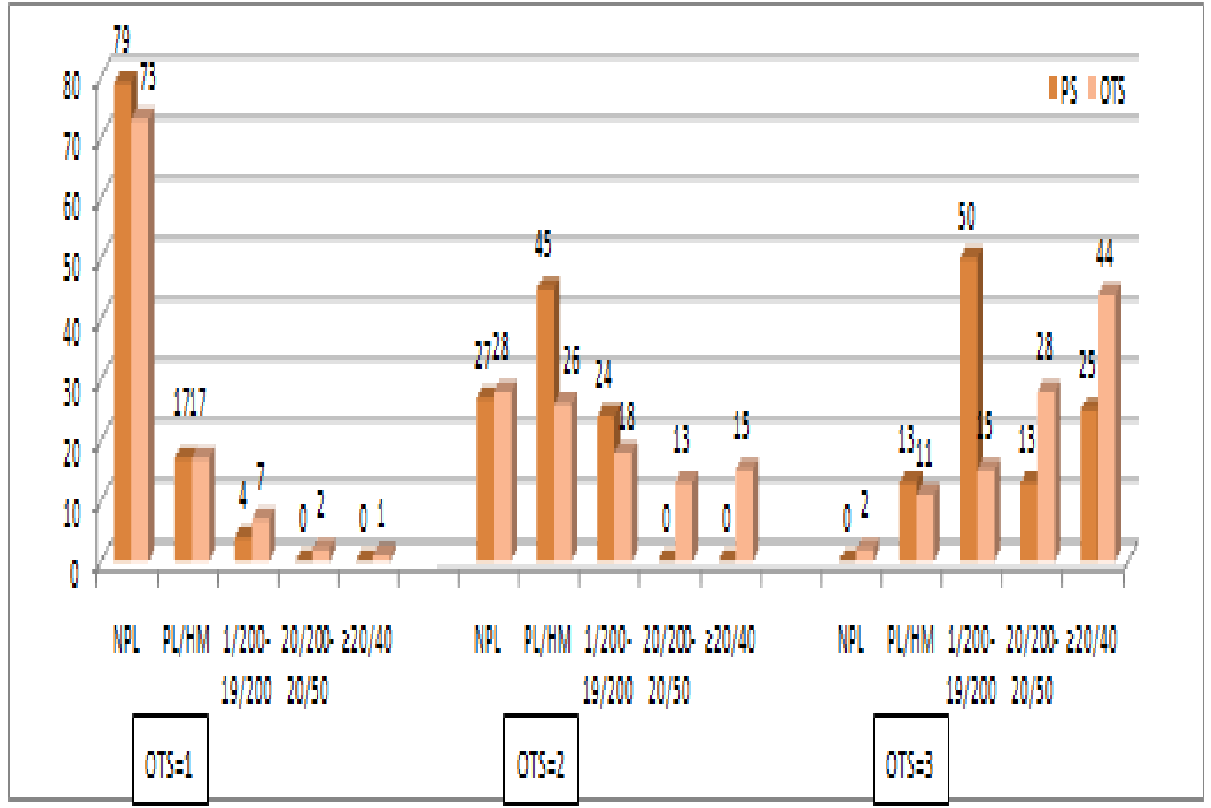

\section{References}

[1]. F. Kuhn, R. Maisiak, L. Mann, V. Mester, R. Morris, and C. D. Witherspoon, "The ocular trauma score (OTS)," Ophthalmology Clinics of North America, vol. 15, no. 2, pp. 163-165, 2002.

[2]. D. J. Pieramici, P. Sternberg Jr., T.M. Aaberg Sr. et al., "A system for classifying mechanical injuries of the eye (globe)," American Journal of Ophthalmology, vol. 123, no. 6, pp. 820-831, 1997.

[3]. A.-D. N'egrel and B. Thylefors, "The global impact of eye injuries," Ophthalmic Epidemiology, vol. 5, no. 3, pp. 143-169, 1998.

[4]. Sengupta P, Mazumdar M, Gyatsho J. Epidemiology of ocular trauma cases presenting to a tertiary care hospital in a rural area in West Bengal, India over a period of 2 years IOSR-JDMS 2016; 15 (3): 92-97.

[5]. Teixeira SM, Bastos RR, Falc ^ao MS, Falc ^ao-Reis FM, Rocha-Sousa AA. Open-globe injuries at an emergency department in porto, Portugal: clinical features and prognostic factors. European Journal of Ophthalmology 2014; 24(6): 932-939.

[6]. Madhusudhan, Evelyn-Tai LM, Zamri N, Adil H, Wan-Hazabbah WH. Open globe injury in Hospital Universiti Sains Malaysia - a 10-year review. International Journal of Ophthalmology 2014; 7(3): 486-490.

[7]. Meng Y, Yan H. Prognostic factors for open globe injuries and correlation of ocular trauma score in Tianjin, China. Journal of ophthalmology 2015.

[8]. Du Toit N, Mustak H, Cook C. Visual outcomes in patients with open globe injuries compared to predicted outcomes using the Ocular Trauma Scoring system. Int J Ophthalmol 2015; 8(6): 1229-33.

[9]. Sengupta P, Mazumdar M, Gyatsho J. Epidemiology of ocular trauma cases presenting to a tertiary care hospital in a rural area in West Bengal, India over a period of 2 years IOSR-JDMS 2016; 15 (3): 92-97.

[10]. Sengupta P, Mazumdar M, Gyatsho J. Epidemiology of ocular trauma cases presenting to a tertiary care hospital in a rural area in West Bengal, India over a period of 2 years IOSR-JDMS 2016; 15 (3): 92-97.

[11]. Gyasi ME, Adjuik MA, Amoaku, WMK. Epidemiology of hospitalized ocular injuries in the Upper East Region of Ghana. Ghana Med J. 2007; 41 (4): 171-175.

[12]. Khatry SK, Lewis AE, Schein OD, Thapa MD. The epidemiology of ocular trauma in rural Nepal. Br J OphthalmoI. 2004; 88: 456-460. 21.

[13]. Vasu U, Vasnaik A, Battu RR, Kurian M, George S. Occupational open globe injuries. Indian J Ophthalmol. 2001; 49: 43-47

[14]. Saari KM, Aine E. Eye injuries in agriculture. Acta Ophthalmol Suppl. 1984; 161: 42-51.

[15]. Meng Y, Yan H. Prognostic factors for open globe injuries and correlation of ocular trauma score in Tianjin, China. Journal of ophthalmology 2015.

[16]. Desai P, Baines P, McEwen CJ, Minassian DC. Incidence of cases of ocular trauma admitted to hospital and incidence of blinding outcome. Br J Ophthalmol. 1996; 80 (7): 592-596.

[17]. Unver YB, Kapran Z, Acar N, Altan T. Ocular Trauma Score in Open-Globe Injuries. J Trauma 2009; 66(4):1030-2.

[18]. Kuhn F, Maisiak R, Mann L, Morris R, Witherspoon C, Pieramici D. The Ocular Trauma Score (OTS): Prognosticating the final vision of the seriously injured eye. Ocul Trauma Princ Pract Thieme N Y 2002;12-4

[19]. Kuhn F, Maisiak R, Mann L, Mester V, Morris R, Witherspoon CD. The Ocular Trauma Score (OTS). $2002 ; 15$ (2): 163-165.

[20]. Yu Wai Man C, Steel D. Visual outcome after open globe injury: a comparison of two prognostic models - the Ocular Trauma Score and the Classification and Regression Tree. Eye (London) 2010; 24(1):84-89.

[21]. Schmidt GW, Broman AT, Hindman HB, Grant MP. Vision survival after open globe injury predicted by classification and regression tree analysis. Ophthalmology 2008; 115(1):202-209. 
[22]. Unver YB, Kapran Z, Acar N, Altan T. Ocular trauma score in open globe injuries.J Trauma 2009; 66(4): 1030-1032

[23]. Shah MA, Shah SM, Applewar A, Patel C, Patel K. Ocular Trauma Score as a predictor of final visual outcomes in traumatic cataract cases in pediatric patients. J Cataract Refract Surg 2012; 38:959-965.

[24]. Sobaci G, Akin T, Erdem U, Uysal Y, Karagul S. Ocular trauma score in deadly weapon-related open-globe injuries. Am J Ophthalmol 2006; 141 (4):760-761.

[25]. Kuhn F, Maisiak R, Mann L, Mester V, Morris R, Witherspoon CD. The Ocular Trauma Score (OTS). $2002 ; 15$ (2): 163-165.

[26]. Du Toit N, Mustak H, Cook C. Visual outcomes in patients with open globe injuries compared to predicted outcomes using the Ocular Trauma Scoring system. Int J Ophthalmol 2015; 8(6): 1229-33.

[27]. Islam Q, Ishaq M, Yaqub MA, Mehboob MA. Predictive value of ocular trauma score in open globe combat eye injuries. J Ayub Med Coll Abbottabad 2016; 28(3):484-8.

[28]. Shah MA, Shah SM, Applewar A, Patel C, Patel K. Ocular Trauma Score as a predictor of final visual outcomes in traumatic cataract cases in pediatric patients. J Cataract Refract Surg 2012; 38:959-965. 